
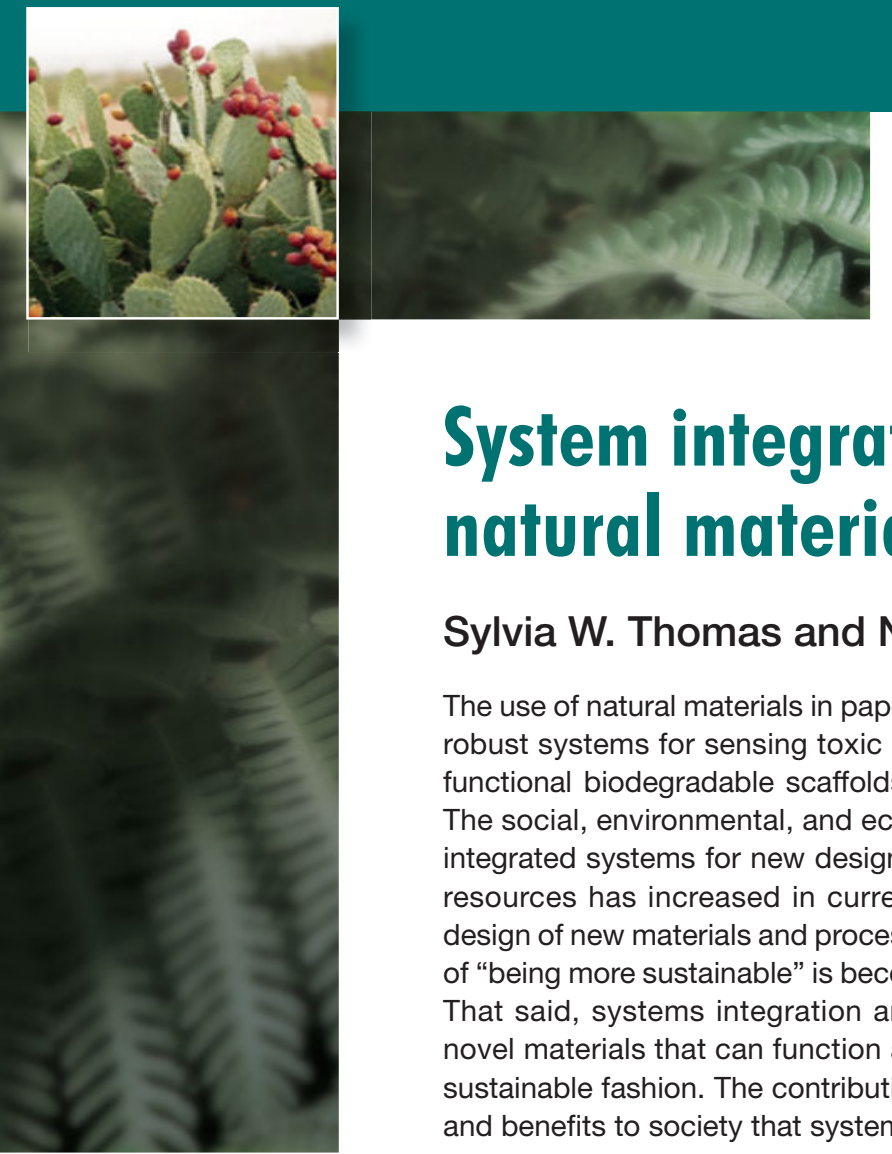

\title{
System integration of functionalized natural materials
}

\author{
Sylvia W. Thomas and Norma A. Alcantar, Guest Editors
}

\begin{abstract}
The use of natural materials in paper and textiles, and in support of tunable and mechanically robust systems for sensing toxic gases, removing pollutants from water, and constructing functional biodegradable scaffolds, is a topic of great scientific and practical importance. The social, environmental, and economic impact of using natural materials to functionalize integrated systems for new designs is imperative, as the need to reuse and recycle natural resources has increased in current manufacturing. The inclusion of sustainability in the design of new materials and processes is almost a common practice; concurrently, the usage of "being more sustainable" is becoming a more conjointly used term in urban conversations. That said, systems integration and natural materials are intrinsically related to produce novel materials that can function as sensors, switches, platforms, and building blocks in a sustainable fashion. The contributions in this issue of MRS Bulletin highlight the importance and benefits to society that systems integration of functional materials can provide.
\end{abstract}

\section{Brief context of system integration of natural materials}

The creation of new materials and products using natural resources has been occurring since ancient times. ${ }^{1}$ After decades of using synthetic materials for many industrial applications (Figure 1), ${ }^{2}$ in the late 1980 s, interest in turning to natural materials started flourishing again, owing to the thrust toward sustainable design with the release of the Brundtland Commission Report. ${ }^{3,4}$ Previous issues of MRS Bulletin have tangentially touched on the use of functional natural materials, including in the construction industry, ${ }^{5,6}$ health applications, ${ }^{7-9}$ energy production and supply, ${ }^{10,11}$ chemical products, ${ }^{12,13}$ fibers, ${ }^{14}$ and sustainable development in general. ${ }^{15,16}$ However, there has not been a complete issue focused on the development of functional materials from natural resources with a systems integration approach. In this issue, materials such as hydrogels, ${ }^{17,18}$ cellulose,,${ }^{19-23}$ paper, ${ }^{24-29}$ cells, ${ }^{30-34}$ plants, ${ }^{35-40}$ nanocomposites, ${ }^{20,21,25,41-43}$ and biomass ${ }^{44-46}$ are featured as the core thematic thread that links how a systems integration approach is the essence of materials design.

\section{The significance of working with natural materials}

Natural materials have emerged as materials of choice for a wide range of applications, ranging from biomedical to energy to environmental. The many attributes of natural materials, such as intrinsic biocompatibility and surface active properties, make them prime sources for state-of-the-art applications. Regarding the use of natural products for medicinal applications, there are many examples such as the integration of aloe vera, genistein from soybean, green tea leaves, carrot root, mango pulp, and more recently, Carvalho's cactus mucilagethe viscous liquid inside cactus pads - in wound healing. ${ }^{47,48}$ Natural plant-based products are classified as phytochemicals and have been found to exhibit anti-inflammatory, antioxidant, antimicrobial, regenerative, and biocompatible properties, and are viewed as safer and more affordable than conventional/ standard therapies..$^{48-52}$

Recent investigations continue to diversify the benefits of using extracts from plants such as cactus mucilage in the functional form of a filtration membrane. ${ }^{38,53,54}$ Opuntia ficusindica cactus mucilage extracts have been functionalized in the form of a nanofiber membrane (Figure 2) for integration into rural or urban point-of-use filtration systems. ${ }^{38,39,53-57}$ Mucilage is a natural, nontoxic, biocompatible, biodegradable, inexpensive, and abundant material and is composed of proteins, monosaccharides, and polysaccharides (Figure 3). Two fractions of the mucilage can be extracted. The solids portion after maceration leads to the gelling extract (GE), which is a pectin-rich polysaccharide; while the nongelling extract (NE), which is considered a galactomannan polysaccharide, can be obtained from the liquid supernatant. ${ }^{39,56,58-61}$ 


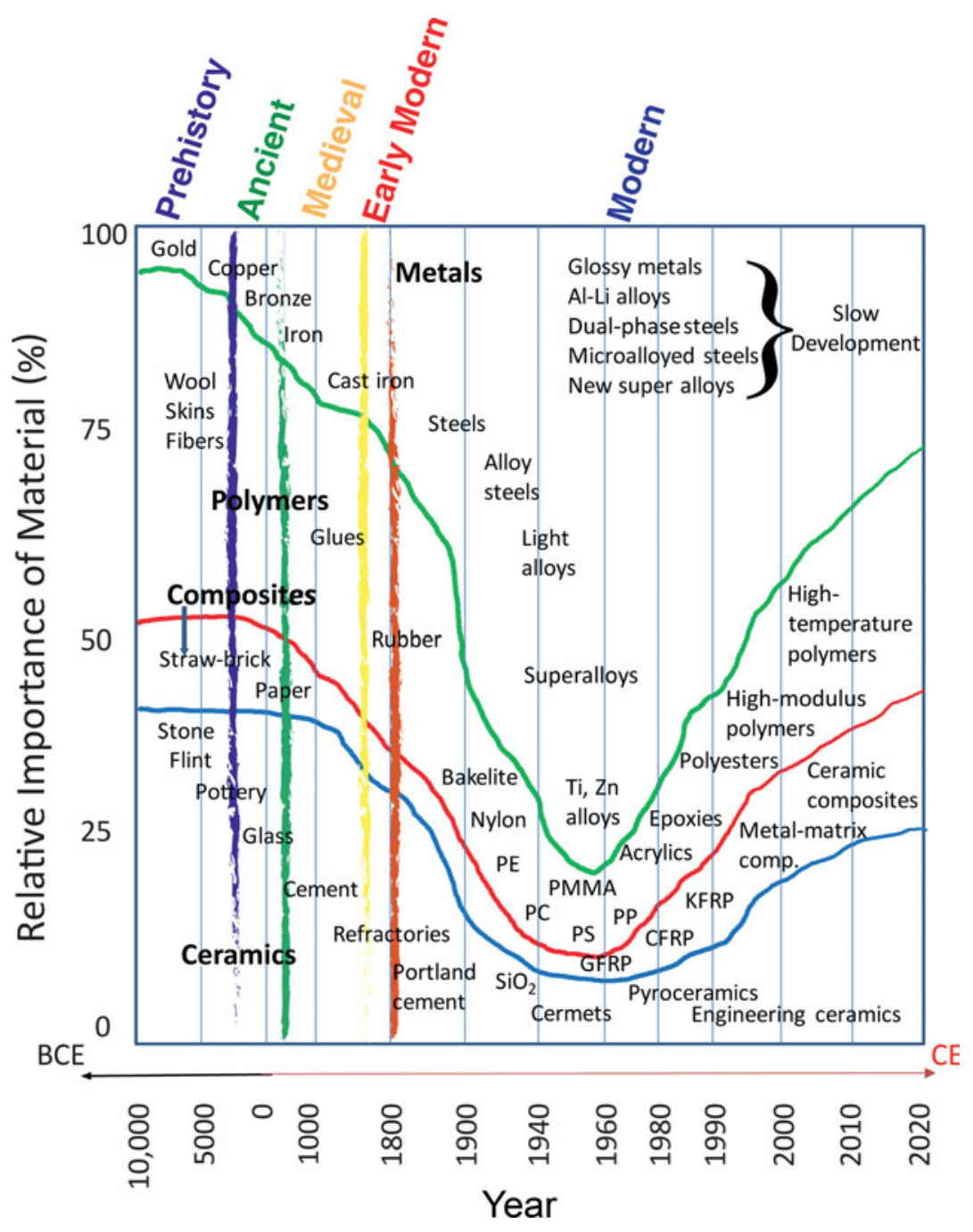

Figure 1. Timeline for the usage of materials from 10,000 Before the Common Era (BCE) to 2020 Common Era (CE). The green, blue, and red curves separate the four main types of materials. (Top to bottom): metals, polymers, composites, and ceramics. Adapted with permission from Reference 2. (C) 2015 Elsevier. Note: PE, polyethylene; PC, polycarbonate; PMMA, poly(methyl methacrylate); PS, polystyrene; PP, polypropylene; GFRP, glass fiberreinforced plastic; CFRP, carbon fiber-reinforced plastic; KFRP, knitted fabric-reinforced polymer.

just 10 min. ${ }^{61}$ When mucilage was added as a pure powder or in membrane form, up to $50 \%$ As or $18-20 \%$ As was removed, respectively. ${ }^{55,57}$ Sibaja et al., ${ }^{62}$ Vollrath et al., ${ }^{14}$ and Truss ${ }^{9}$ have also used natural fibers in functional applications such as textiles and tissue scaffolds. These studies elucidate that mucilage nanofiber membranes, silks, and biocomposite fibers have the potential to serve as the basis for the next generation of economically sustainable filtration devices that make use of a natural nontoxic material for sustainable systems integration designs.

Nanocomposites, polymer hybrids, hydrogels, and cactus mucilage have also been demonstrated as natural dispersants, ${ }^{15,19,26,44,63-65}$ hence, they have the potential of being used for oil spill cleanup operations. ${ }^{65}$ It is well known that extensive damage to marine and wildlife habitats can occur due to oil spills. Chemical dispersants can potentially bioconcentrate (when dispersant concentration exceeds that in water), causing damage to the marine life and environment. On the other hand, the use of surface active natural chemicals leads to nontoxic dispersants. John et al. ${ }^{66,67}$ have developed biobased dispersants that can gelate crude oil and enhance its recovery. ${ }^{66,68}$ Similarly, NE and GE extracts from the cactus plant can be made less toxic by formulating oil-in-water $(\mathrm{O} / \mathrm{W})$ emulsions (Figure 3). Mucilage disperses oil in $\mathrm{O} / \mathrm{W}$ emulsions by lowering the surface and interfacial tension. Higher emulsion stabilities were shown to have smaller droplet size in the systems with cactus mucilage. ${ }^{61,65}$

Toxicity is also an important issue to consider when working with natural materials. According to the US Environmental Protection Agency (US EPA) toxicity categories are used to classify chemicals based on their acute toxicity (US EPA, 2010b). ${ }^{69}$ One of the most common parameters to measure toxicity is the

Mucilage as an organic material is capable of interacting with metals, cations, and biological substances promoting flocculation-clumping pollutants into flocs-for removing arsenic, bacteria such as Escherichia coli and Bacillus cereus, and other particulates from drinking water (Figure 4). ${ }^{56,59,61,65}$ This natural material has the potential to be used as a sustainable method for water filtration and contaminant sensing. A mucilage nanofiber membrane has been integrated into a filtration system to treat a 50-parts-per-billion (ppb) arsenic solution. Results demonstrate the natural functionality of the mucilage to absorb arsenic (As) atoms in the filtration system, and this is measured from filtration data in terms of the percentage of arsenic removed. ${ }^{38}$ For instance, when mucilage was added in combination with iron, $>90 \%$ removal of As was attained in
$\mathrm{LC}_{50}$, which stands for the lethal concentration of a substance that causes $50 \%$ of a population of selected sensitive organisms to perish after $24 \mathrm{~h}$ of exposure. If the $\mathrm{LC}_{50}$ is less than $100 \mathrm{mg} / \mathrm{L}$, by convention, the chemical in question can be considered toxic. The lesser the value of $\mathrm{LC}_{50}$, the more toxic a chemical. In our experience, mucilage from cactus, such as the NE and GE extracts, would be classified as practically nontoxic. When aquatic life is exposed to the mucilage, specifically Daphnia magna, the survival rate is almost $100 \%$ for concentrations equal to or lower than $100 \mathrm{mg} / \mathrm{L}$. For concentrations ranging from $200-2000 \mathrm{mg} / \mathrm{L}$ of GE and NE, the survival rate of Daphnia was higher than $70 \%$. In general, nonexistent toxicity is a beneficial property of working with natural materials. The contribution by Medina-Velo et al. shows in detail how 


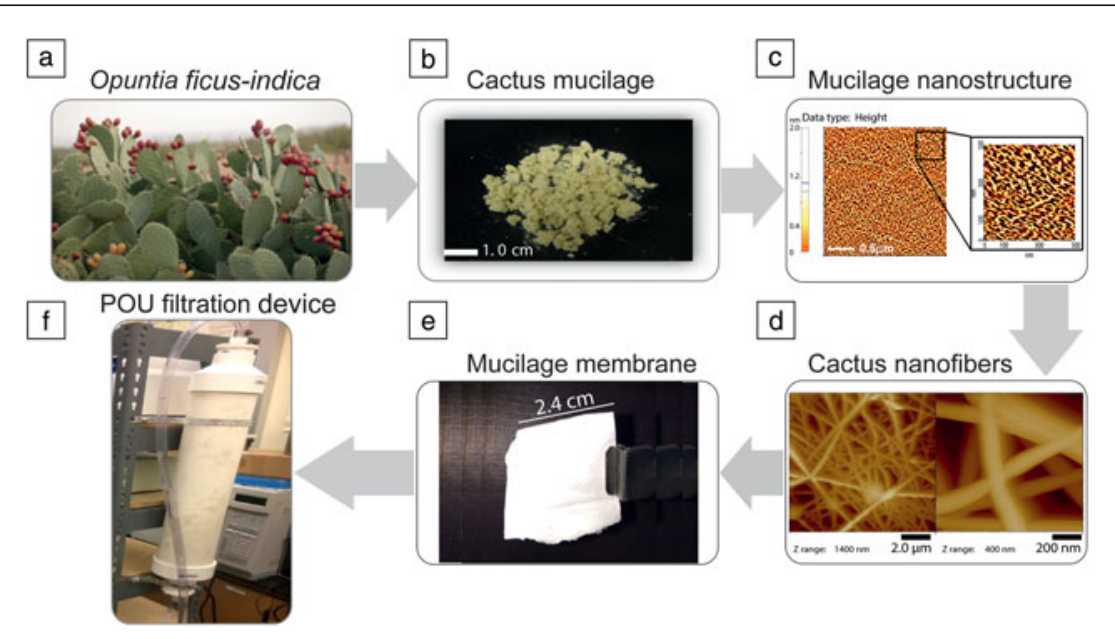

Figure 2. Example of the use of natural materials for the system integration in a point-of-use (POU) filtration system. The cactus mucilage is extracted from the (a) Opuntia ficus-indica plant. (b) It is then dried and ground into a fine powder. (c) Atomic force microscope (AFM) scans of the nanostructure for the nongelling (NE) cactus mucilage extract show a fishing net-like topography. The AFM scans reveal the nanostructure of the NE extract at (right) high $(500 \mathrm{~nm})$ and (left) low magnification $(2 \mu \mathrm{m})$. The color bar scale on the left-hand side shows the color scheme depending on the depth of the scanned surface. Next, cactus mucilage is processed into nanofibers by electrospinning. (d) The subsequent AFM images show greater details of the nanofiber structure; respective scales noted. All AFM scans were taken in height mode. (e) This image shows a typical electrospun membrane. The typical area of the membranes ranged between 2.5 and $3.0 \mathrm{~cm}^{2}$. (f) The membranes are then assembled into water purification filters. ${ }^{38,39,53-57}$

such systems can be integrated into watertreatment technologies. There are several other natural materials that offer critical benefits to systems integration of functional natural materials, and these will be discussed in the different contributions in this issue. Figure 5 shows a schematic representation of the contributions for this issue in regards to the integration of natural materials into functionalized sustainable systems. For instance, it illustrates how natural materials such as cellulose, lignin, cactus plants, biomass, and cells can be processed to produce paper for light, nonpower sensor applications, lignin nano- and macroparticulates, membrane filtration systems for water purification, bio-oils for energy and highstrength polymers, and functionalized tissue substrates. It is also worth mentioning that the analysis of how natural materials react to potential contaminants produced during nanomanufacturing will be discussed in this issue.

\section{In this issue \\ Fabrication of functional tissue}

Natural polymers and polysaccharides are of particular interest as nano- and macrostruc-

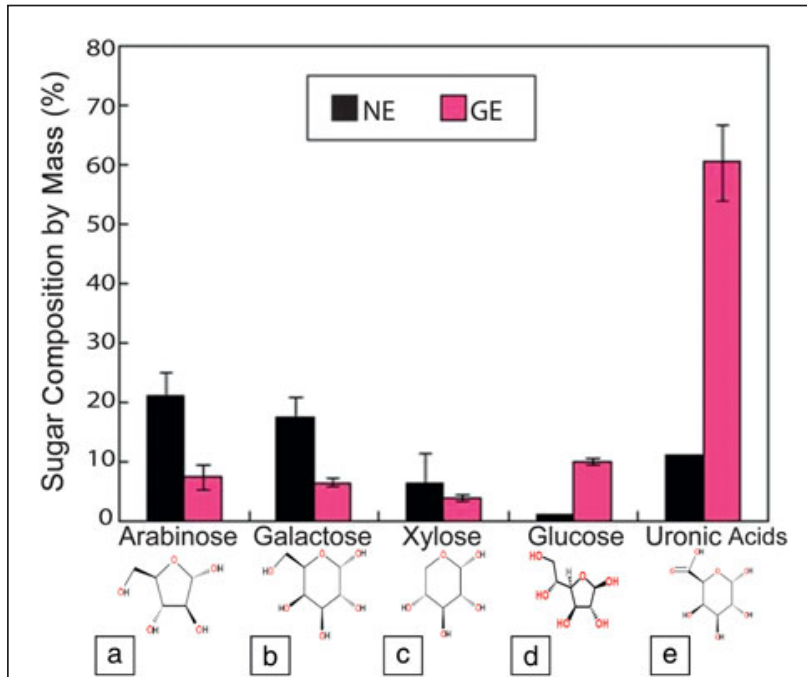

Figure 3. Proteins, monosaccharides, and polysaccharides of mucilage gelling extract (GE) and nongelling extract (NE) are composed of the following main sugars: (a) arabinose, (b) galactose, (c) xylose, (d) glucose, and (e) uronic acids (e.g., hexoses and pentoses sugars). ${ }^{39,56,58-61} \mathrm{GE}$ is a pectin-rich polysaccharide; hence, it contains more uronic acid-type sugars than NE. Conversely, the NE has a higher arabinose and galactose content than GE.

toxicity could be a significant problem in plant biology when plants are exposed to different kinds of materials.

The previous examples mentioned that cactus mucilage properties demonstrate the ability of a natural material to be immersed in fresh and aquatic water systems, and how tures for wound care, skin grafting, and tissue engineering due to their chemical and biological properties, which mimic the extracellular matrix (ECM) to recreate the conditions needed for the physical bioenvironment and the biochemical reactions around cells. ${ }^{70}$ As the ECM provides structural and biochemical support to cells, an electrospun matrix of a polysaccharide-based natural material and biodegradable polymer has the potential to produce a biomembrane that can promote cell proliferation. This strategy of functionalizing a three-dimensional (3D) matrix of natural materials to be integrated for tissue engineering systems to promote cellular migration, proliferation, and growth can be viewed as a "top-down" outlook. ${ }^{17,30,32}$

In their article in this issue, Baksh et al. review an innovative method for bottom-up integration, which utilizes natural cell-cell junctions as in an ECM to build functional tissue layer by layer. The stacking of cells layer by layer on thermally responsive polymers in a three-dimensional (3D) environment produces "engineered cell sheets." There is great promise for the utilization of engineered cell sheets for integration and direct adhesion to existing tissue in vitro or in vivo, without the use of intermediate scaffolds. This form of bottom-up integration functionalizes engineered cell sheets to mimic living cell proliferation and growth for tissue systems or tumors. ${ }^{31,34}$ Cell sheet engineered functional constructs have been integrated successfully in clinical trials and several surgical applications. With this advancement, there are still research questions that must be resolved regarding intercellular response from cell-cell and cell-release (i.e., cell detachment). 

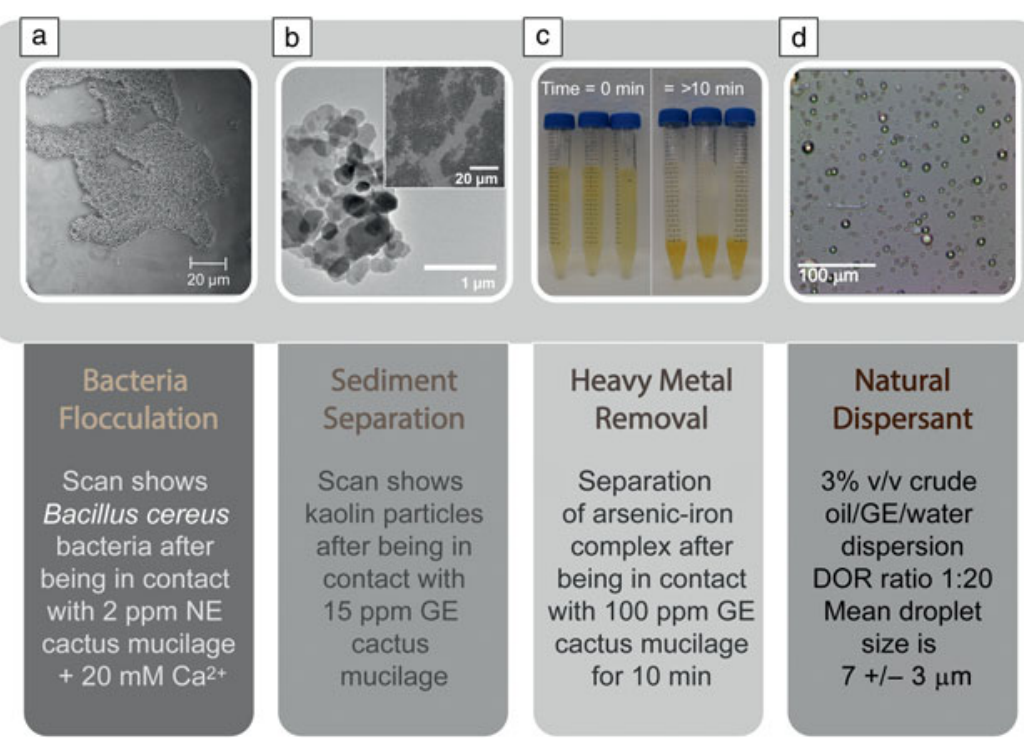

Figure 4. Functional applications of cactus mucilage. In all cases, cactus mucilage has been added to separate/flocculate contaminants at minute concentrations (i.e., between 2 and 100 ppm). ${ }^{56,59,61,65}$ (a) Nongelling extract (NE) can effectively flocculate bacteria from solution. Gelling extract (GE), can effectively remove (b) sediments and (c) heavy metals when added to water. The inset in (b) is a lower magnification image. (d) Effectiveness of cactus mucilage as a dispersant. The example shows crude oil droplets for $3 \%$ volume/volume oil/water dispersions (3\% v/v). The dispersant/oil ratio (DOR) is 1:20.

\section{Functional materials from biomass}

In energy, polymeric materials, based on valorization (i.e., real cost of the materials that considers the cost for their extraction, manufacturing, reuse, and end-of-life processes) of bio-based derived materials and renewable feedstocks, can be a critical alternative to fossil resources. High-performance biopolymers and bioresins use lignocellulosic biomass, which is generally obtained from plant-based materials such as agricultural residues, forestry wastes, and energy crops. In their article, Sibaja Hernández et al. report on these new polymeric materials that have a unique combination of thermal resistance and superior mechanical performance of polymeric resins, sufficient to compete with high-performance structural polyurethanes. Similarly, bio-oils can also be used as building blocks for high-performance biopolymers and bioresins with special surface active properties. ${ }^{44,71}$ Similar to the cactus mucilage composition, bio-oils also contain high-value sugar and carbohydrates, which make them suitable to form fibers for membranes. ${ }^{72}$ In addition, this article includes discussion of techniques that make possible

\section{Functional paper for microfluidic devices}

Microfluidic paper capitalizes on the rich natural porous characteristics of pulp (fiber-like cellulose material). In their article, Böhm and Biesalski review platforms for microfluidic paper devices, which have great flexibility for "manipulating fluid streams" by capillary action. The diversification of paper-based microfluidic systems ranges from medical to environmental applications..$^{26,27,29}$ Several techniques are used to functionalize paper-based devices, including 3D splitting, mixing, or filtering delays. That is, these three forms of fluid transport were described as the separation of fluid into multiple streams (splitting); combining of fluid streams into a single channel (mixing); and separation from the fluid by a membrane (filtering). Microfluidic paper devices can be integrated into several systems, from DNA diagnostics to food-quality control.

This article also discusses the effects of the chemistry and structure of paper in its capacity to be chemically modified to increase its hydrophobicity. Such functionalization has been shown to have a large effect on capillary forces, which are used to control the flow direction and rate in paperbased microfluidic devices. The advantages of using paper as a platform in microfluidics include its low cost, versatility for being integrated with other materials and electronic systems, ease of use, and complete biodegradation after use. The applications of such functional materials is elegantly presented as a function of porosity, surface chemistry, and fiber structure, and the article evaluates the effects of such parameters in a general application involving DNA testing. the transformation of biomass into sustainable-energy sources, which have been regarded as transformative in the way biooils are utilized in polymer engineering.

\section{Functional nano- and microparticles from lignin}

The processing of lignin can also form new functional particles. Rojas and colleagues have been pioneers in the field of functional cellulosic crystals with nano- and microscales for various applications such as in new chemical, superhydrophobic surfaces, emulsifiers, adhesives, sensing devices, and bioscaffolds. ${ }^{20,21,24,42}$ Lignin has been of interest because it is durable and resistant to chemical attack. At the same time, it can be biodegraded by some microorganisms making it a suitable material for "green" applications. The lignin nanoparticles can be functionalized with metals and dielectrics to enhance their applicability in energy storage systems. In their article, Ago et al. present techniques for the processing of lignin particles such as self-assembly, extrusion, or coalescence. Such techniques are also important for processing other natural materials with similar properties into drug carriers, dispersants, food emulsifiers, and compound encapsulates. They also discuss how different colloidal properties can be finely controlled, depending on the type, size, and chemistry of the lignin particles.

\section{Assessing the effects of functional materials via plant uptake mechanisms}

For quite some time, we have been questioning what effects, if any, nano- or microscale materials have in plants as well as 


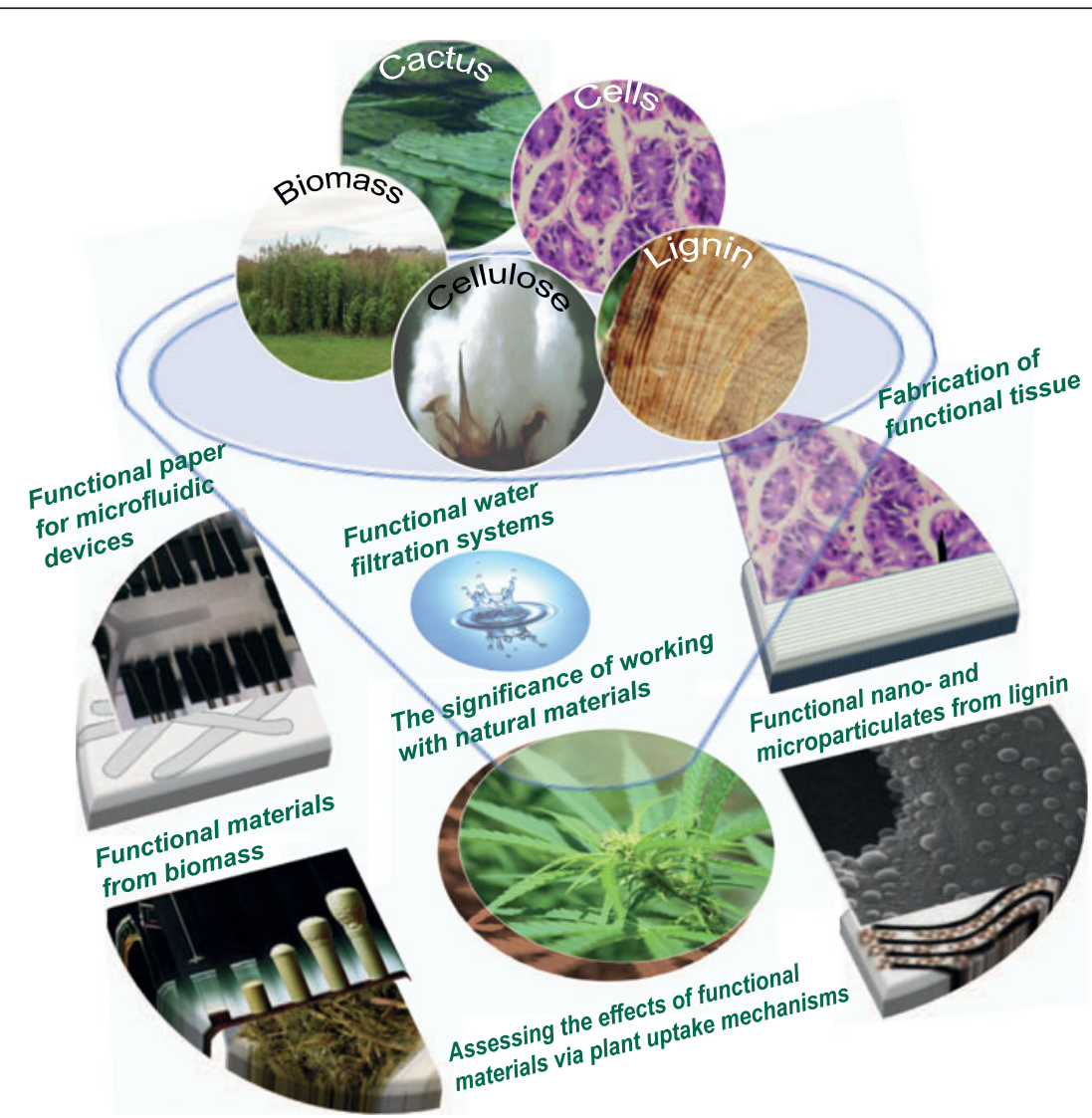

Figure 5. Schematic representation of the contributions for this issue related to the theme, "System integration of functionalized natural materials." From top right, counterclockwise: Baksh et al. illustrate the preparation of functionalized tissue substrates. Böhm et al. demonstrate the transformation of cellulose fiber into sensors made of functionalized paper. Sibaja Hernández et al. discuss the integration of the production of bio-oils for functionalized polymeric systems in the realm of biomass. Medina-Velo et al. depict plant uptake and transport mechanisms of different metal contaminants that affect plant growth and integrity. Ago et al. show the preparation of functionalized cellulosic fibers with lignin nanoparticles for antibacterial, antioxidant, and colloid active substrates. discern how nanoscale metals interact with plant biology and their effect on several food crops such as tomatoes, soybean, corn, and cucumbers, where the type of metal and chemistry plays a significant role in how the plant reacts to their presence.

\section{System integration in sustainable design}

Federal agencies started recognizing the importance of supporting projects that touched on the integration of natural materials in sustainable design. In the early 1990s, the EPA and the National Science Foundation (NSF) started supporting projects that included sustainable materials and processes. The NSF implemented "Biocomplexity in the Environment Programs" in the early 2000s. Consequently, the "Materials Use: Science, Engineering and Society" Program was promoted in 2003 with approximately USD $\$ 65$ million investment. Subsequently, the creation of various institutes for sustainability along with different undergraduate and graduate curricula that relate to this issue increased exponentially. The current program that supports research and development across disciplines in this area is the "Sustainable Chemistry, Engineering, and Materials Program" at NSF. The great majority of technologies, new materials, and novel designs that resulted from such initiatives have shown that system integration of natural materials is key to enhancing our understanding of how to best learn from nature. their fate in the environment. Gardea-Torresday's group is a pioneer in this area and has been able to evaluate how these mechanisms take place in plants. One of the main concerns is whether engineered nanomaterials (ENMs) such as $\mathrm{CeO}_{2}$, $\mathrm{SiO}_{2}, \mathrm{ZnO}$, or $\mathrm{TiO}_{2}$ enhance or inhibit the functionalities of biological, agricultural, and environmental systems. What is known is the natural ability of plants to adhere to an uptake or transport process, which is the elemental transition from soil to root or roots to tissues.

In their article in this issue, Medina-Velo et al. discuss the uptake and translocation of ENMs and the interactions with plant roots, tissue, and seeds. When natural plants are integrated into a system, there is the potential for the behavior of the system to change after the uptake of ENMs. The authors offer a unique perspective that shows the alarming amounts of ENMs produced per year and their potential effects. ${ }^{24,39}$ They have discovered that the mechanisms in plants are unique. Both a synchrotron micro x-ray fluorescence imaging technique and $\mathrm{x}$-ray absorption near-edge structure were able to

\section{Summary}

The successful application of natural materials in the construction of membranes, filtration devices, sensors, organic electronics, flexible smart materials, support structures, hydrated systems, chemical synthesis, and hydrophobic surfaces are displayed in the articles in this issue of MRS Bulletin. The contributions present various types of functionalized natural materials/composites engineered for high chemical and mechanical performance, which have a significant role in manufacturing and materials flow analysis. The benefits of fundamental science related to natural systems include prime relationships to sustainability such as life-cycle assessments, and life-cycle costs in health and safety that will continue to pave pathways to transform materials science and create better materials systems.

\section{Acknowledgments}

The authors gratefully acknowledge the support of the Gulf of Mexico Research Initiative and the National Science 
Foundation's awards on Collaborative Research-SusChEM: Graded Interpenetrating Polymer Membranes Based on Sustainable Materials for Selective Removal of Organics from Water (CBET: 1512225) and EAGER: Fabrication, Characterization, and Implementation of an OFI Mucilage Nanofiber Membrane System (CBET: 1241582).

\section{Financial Disclosure}

N.A. Alcantar is an inventor of the following technologies, each of which is related to the project and is licensed by Water, Health, and Sustainability, LLC: Water Purification Method Using Plant Molecules (USF Tech ID 06A004PRC); Composition and Method to Reduce Sediment and Bacterial Contamination from Water (USF Tech ID USF 06A004PR2C); Use of Cactus Mucilage as a Dispersant and Absorbant for Oil in Oil-Water Mixtures (USF Tech ID USF 10A064); and Cactus Mucilage and Ferric Ions for the Removal of Arsenate (As[V]) from Water (USF Tech ID USF 11B122). N.A. Alcantar and S.W. Thomas are inventors of the following technology, which is also licensed by Water, Health, and Sustainability, LLC: Electrospun Cactus Mucilage Nanofibers (USF Tech ID 11A082).

\section{References}

1. W.D. Callister Jr., D.G. Rethwisch, Materials Science and Engineering: An Introduction (Wiley, New York, 2014).

2. H.-C. Möhring, C. Brecher, E. Abele, J. Fleischer, F. Bleicher, CIRP Ann.-Manuf. Technol. (2), 725 (2015).

3. D.R. Durham, Manuf. Eng. 131 (3), 16 (2003).

4. World Commission on Environment and Development, Our Common Future (Oxford University Press, Oxford, UK, 1987).

5. P. Bonfield, MRS Bull. 33 (4), 454 (2008).

6. K.E. Kurtis, MRS Bull. 40 (12), 1102 (2015)

7. N. Kossovsky, D. Millett, MRS Bull. 16 (9), 78 (1991).

8. S.S. Liow, A.A. Karim, X.J. Loh, MRS Bull. 41 (7), 557 (2016).

9. R.W. Truss, MRS Bull. 36 (9), 711 (2011)

10. A.J. Hurd, R.L. Kelley, R.G. Eggert, M.-H. Lee, MRS Bull. 37 (4), 405 (2012).

11. A.Y. Ku, A.P. Shapiro, MRS Bull. 37 (4), 439 (2012).

12. W.G. Glasser, MRS Bull. 19 (2), 46 (1994)

13. P.J. Halley, J.R. Dorgan, MRS Bull. 36 (9), 687 (2011).

14. F. Vollrath, D. Porter, C. Holland, MRS Bull. 38 (1), 73 (2013).

15. M.L. Green, L. Espinal, E. Traversa, E.J. Amis, MRS Bull. 37 (4), 303 (2012).

16. K. Halada, R. Yamamoto, MRS Bull. 26 (11), 871 (2001).

17. 0.0. Akintewe, S.J. DuPont, K.K. Elineni, M.C. Cross, R.G. Toomey, N.D. Gallant, Acta Biomater. 11, 96 (2015).

18. R. Toomey, A. Vidyasagar, 0. Ortiz, "Swelling Behavior of Thin Hydrogel Coatings," in Functional Polymer Films, W. Knoll, R.C. Advincula, Eds. (Wiley-VCH, Weinheim, Germany, 2011), pp. 649-667.

19. M.A. Hubbe, O.J. Rojas, M. Fingas, B.S. Gupta, BioResources 8 (2), 3038 (2013).

20. M.A. Hubbe, O.J. Rojas, L.A. Lucia, M. Sain, BioResources 3 (3), 929 (2008).

21. Y. Habibi, L.A. Lucia, O.J. Rojas, Chem. Rev. 110 (6), 3479 (2010).

22. M.W. Ott, H. Herbert, M. Graf, M. Biesalski, Polymer 98, 505 (2016)

23. M. Jocher, M. Gattermayer, H.J. Kleebe, S. Kleemann, M. Biesalski, Cellulose 22 (1), 581 (2015).

24. M.A. Hubbe, R.A. Venditti, 0.J. Rojas, BioResources 2 (4), 739 (2007).

25. J.R. Peralta-Videa, L.J. Zhao, M.L. Lopez-Moreno, G. de la Rosa, J. Hong, J.L. Gardea-Torresdey, J. Hazard. Mater. 186 (1), 1 (2011).

26. C. Dubois, N. Herzog, C. Ruttiger, A. Geissler, E. Grange, U. Kunz, H.J. Kleebe, M. Biesalski, T. Meckel, T. Gutmann, M. Gallei, A. Andrieu-Brunsen, Langmuir 33 (1), 332 (2017).

27. A. Bohm, F. Carstens, C. Trieb, S. Schabel, M. Biesalski, Microfluid. Nanofluid. 16 (5), 789 (2014).

28. J.L. Song, O.J. Rojas, Nord. Pulp Pap. Res. J. 28 (2), 216 (2013)

29. C. Ruettiger, S. Mehlhase, S. Vowinkel, G. Cherkashinin, N. Liu, C. Dietz, R.W. Stark, M. Biesalski, M. Gallei, Polymer 98, 429 (2016).

30. M. Zhernenkov, R. Ashkar, H. Feng, 0.0. Akintewe, N.D. Gallant, R. Toomey,

J.F. Ankner, R. Pynn, ACS Appl. Mater. Interfaces 7 (22), 11857 (2015).
31. M.M. Maisonet, K.K. Elineni, R.G. Toomey, N.D. Gallant, ACS Biomater. Sci. Eng. 1 (11), 1163 (2015)

32. M.C. Cross, R.G. Toomey, N.D. Gallant, Biomed. Mater. 11 (2), (2016), doi:10.1088/1748-6041/11/2/022002.

33. L. Patra, J.M. Messman, R. Toomey, Soft Matter 9 (16), 4349 (2013)

34. R. Falahat, M. Wiranowska, R. Toomey, N. Alcantar, Vib. Spectrosc. 87, 164 (2016)

35. C. Alvarez, O.J. Rojas, B. Rojano, P. Ganan, BioResources 10 (1), 672 (2015). 36. M.A. Hubbe, O.J. Rojas, L.A. Lucia, BioResources 10 (3), 6095 (2015).

37. D. Stebbins, A.L. Buttice, D. Fox, D.M. Smith, N.A. Alcantar, "Cactus Mucilage as an Emergency Response Biomaterial to Provide Clean Drinking Water," in Monitoring Water Quality: Pollution Assessment, Analysis, and Remediation, S. Ahuja, Ed. (Elsevier, Oxford, UK, 2013), pp. 249-260.

38. S.W. Thomas, M. Devisetty, H.C. Katakam, S. Perez, F. Guo, D. Stebbins, N. Alcantar, R. Muppaneni, "Investigation of Novel Opuntia ficus-indica Mucilage Nanofiber Membrane Filtration for Water Systems," Mater. Res. Soc. Symp. Proc. 1745, J. Abelson, C.-G. Granqvist, E. Traversa, Eds. (Materials Research Society, Warrendale, PA, 2015), pp. ff04-05

39. K.A. Young, A. Anzalone, T. Pichler, M. Picquart, N.A. Alcantar, "The Mexican Cactus as a New Environmentally Benign Material for the Removal of Contaminants in Drinking Water," Mater. Res. Soc. Symp. Proc. 930, M.A. Shannon, D. Ginley, A.M. Weiss, Eds. (Materials Research Society, Warrendale, PA, 2006), pp. JJ01-01. 40. S. Bandyopadhyay, J.R. Peralta-Videa, J.L. Gardea-Torresdey, Environ. Eng. Sci. 30 (3), 118 (2013).

41. A. Geissler, F. Loyal, M. Biesalski, K. Zhang, Cellulose 21 (1), 357 (2014).

42. C. Salas, T. Nypelo, C. Rodriguez-Abreu, C. Carrillo, O.J. Rojas, Curr. Opin Colloid Interface Sci. 19 (5), 383 (2014).

43. M.L. Auad, M.A. Mosiewicki, T. Richardson, M.I. Aranguren, N.E. Marcovich J. Appl. Polym. Sci. 115 (2), 1215 (2010).

44. J. Trujillo-Reyes, J.R. Peralta-Videa, J.L. Gardea-Torresdey, J. Hazard. Mater 280, 487 (2014)

45. N. Wei, B.K. Via, Y.F. Wang, T. McDonald, M.L. Auad, Ind. Crops Prod. 57, 116 (2014).

46. Y. Celikbag, T.J. Robinson, B.K. Via, S. Adhikari, M.L. Auad, J. Appl. Polym Sci. $132(28), 42239$ (2015)

47. E.G. Carvalho, C.P. Soares, L. Blau, R.F. Menegon, W.M. Joaquim, Brazilian J. Pharmacogn. 24 (6), 677 (2014)

48. N. Tabassum, M. Hamdani, Pharmacogn. Rev. 8 (15), 52 (2014).

49. V. Andreu, G. Mendoza, M. Arruebo, S. Irusta, Materials 8 (8), 5154 (2015).

50. Y. Har-el, J. Gerstenhaber, R. Brodsky, R. Huneke, P. Lelkes, Wound Med 5, 9 (2014)

51. L.K. Lin, A. Perets, Y.E. Har-el, D. Varma, M.Y. Li, P. Lazarovici, D.L. Woerdeman, P.I. Lelkes, J. Tissue Eng. Regen. Med. 7 (12), 994 (2013).

52. R.K. Sivamani, B. Ma, L. Wehrli, E. Maverakis, Adv. Wound Care 1 (5) $213(2012)$

53. S.W. Thomas, Y. Pais, N.A. Alcantar, "Electrospun Cactus Mucilage Nanofibers," US Patent 9,555,392 (2012).

54. S.W. Thomas, N.A. Alcantar, Y. Pais, "Electrospinning and Characterization of Novel Opuntia ficus-indica Mucilage Biomembrane," Mater. Res. Soc. Symp. Proc. 1480, P.S. Bermudez, J. Majewski, N. Alcantar, A. Hurd, Eds. (Materials Research Society, Warrendale, PA, 2012), pp. S2B-0017.

55. V. Eppili, "Electrospinning of Polymeric Solutions Using Opuntia ficus-Indica Mucilage and Iron Oxide for Nanofiber Membranes for Treating Arsenic Contaminated Water," graduate thesis, University of South Florida, Tampa, FL (2016).

56. A.L. Buttice, J.M. Stroot, D.V. Lim, P.G. Stroot, N.A. Alcantar, Environ. Sci. Technol. 44 (9), 3514 (2010).

57. X. Vecino, R. Devesa-Rey, D.M. de Lima Stebbins, A.B. Moldes, J.M. Cruz, N.A. Alcantar, Environ. Technol. Innov. 6, 69 (2016).

58. N.A. Alcantar, B. Joseph, K. Young, "Water Purification Method Using Plant Molecules for Removal of Arsenic," US Patent US7943049 B1, University of South Florida, Tampa, FL (2007).

59. A.L. Buttice, N.A. Alcantar, "Sediment Removal with the Opuntia ficus Indica Cactus: A Water Purification Method for Communities in Latin America," in Comprehensive Water Quality and Purification, S. Ahuja, Ed. (Elsevier, New York, 2014), vol. 1, p. 98

60. D.I. Fox, T. Pichler, D.H. Yeh, N.A. Alcantar, Environ. Sci. Technol. 46 (8), 4553 (2012).

61. D.I. Fox, D.M. Stebbins, N.A. Alcantar, Environ. Sci. Technol. 50 (5), 2507 (2016). 62. B. Sibaja, E. Culbertson, P. Marshall, R. Boy, R.M. Broughton, A.A. Solano, M. Esquivel, J. Parker, L. De la Fuente, M.L. Auad, Carbohydr. Polym. 134, 598 (2015)

63. V. Jabbari, J.M. Veleta, M. Zarei-Chaleshtori, J. Gardea-Torresdey, D. Villagran, Chem. Eng. J. 304, 774 (2016).

64. P.K. Vemula, G. John, Acc. Chem. Res. 41 (6), 769 (2008).

65. N.A. Alcantar, D.I. Fox, S. Thomas, R.G. Toomey, "Use of Cactus Mucilage as a Dispersant and Absorbant for Oil in Oil-Water Mixtures," US Patent 9,163,374, University of South Florida, Tampa, FL (2012). 
66. S.R. Jadhav, P.K. Vemula, R. Kumar, S.R. Raghavan, G. John, Angew. Chem. Int. Ed. 49 (42), 7695 (2010).

67. G. John, B.V. Shankar, S.R. Jadhav, P.K. Vemula, Langmuir 26 (23), 17843 (2010)

68. K.P. Divya, M. Miroshnikov, D. Dutta, P.K. Vemula, P.M. Ajayan, G. John, Acc. Chem. Res. 49 (9), 1671 (2016).

69. D.L. Denton, J.M. Miller, R.A. Stuber, 2007 EPA Regions 8, 9, and 10 Toxicity Training Tool (TTT), (US Environmental Protection Agency, San Francisco, 2010).

70. J.F. Mano, G.A. Silva, H.S. Azevedo, P.B. Malafaya, R.A. Sousa, S.S. Silva, L.F. Boesel, J.M. Oliveira, T.C. Santos, A.P. Marques, N.M. Neves, R.L. Reis, J. R. Soc. Interface 4 (17), 999 (2007)

71. S.A. Bird, D. Clary, K.C. Jajam, H.V. Tippur, M.L. Auad, Polym. Eng. Sci. 53 (4), 716 (2013).

72. N.E. Marcovich, M.L. Auad, M.I. Aranguren, "Responsive Nanocellulose Composites," in Handbook of Green Materials: Processing Technologies, Properties and Applications, K. Oksman, A.P. Mathew, A. Bismarck, O. Rojas, M. Sain, Eds. (World Scientific, Singapore, 2014), vol. 2, p. 181.

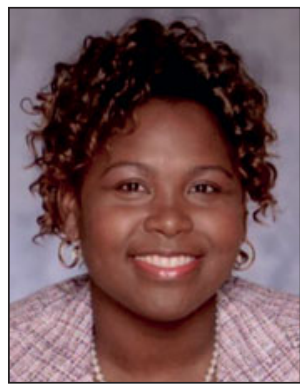

Sylvia W. Thomas is an associate professor in electrical engineering and leads the Advanced Materials Bio and Integration Research Laboratory at the University of South Florida (USF). She joined the USF system in 2005 as the assistant dean in the College of Engineering. She received her bachelor's and master's degrees in electrical engineering in 1988 and 1990, respectively, from Vanderbilt University. She received her $\mathrm{PhD}$ degree in electrical engineering with a concentration in electronic device materials from Howard University in 1999. Thomas has published several articles, book chapters, and holds six patents. She is a member of the National Academy of Inventors and a 2012 McKnight Junior Faculty Fellow. She has received numerous awards, including an NSF Materials Research Science and Engineering Center Fellowship and the 2015 USF-Graduate Faculty Mentor Award. Her current research interests include processing and characterizing biomembranes, nanocomposites, biocompatible materials, and polymers for biomedical, water purification, energy harvesting, and electronic devices. Thomas can be reached by phone at 813974-4011 or by email at sylvia@usf.edu.

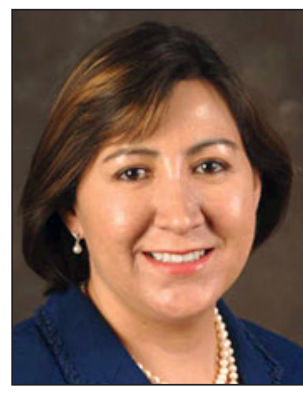

Norma A. Alcantar is a professor in the Department of Chemical and Biomedical Engineering at the University of South Florida (USF). She is director of the Alfred P. Sloan Foundation Minority Scholars Program; co-director of the Water, Health, and Sustainability Graduate Certificate; and the director of the Materials Science and Engineering Graduate Certificate. She received her bachelor's degree in chemical engineering in 1993 at the Universidad National Autónama de México, and her doctorate degree in chemical engineering at the University of California, Santa Barbara, in 2000. Her numerous awards include the 2010 USF-Hispanic Pathways Award, a 2016 Excellence in Innovation Award by the National Academy of Inventors, and a 2016-2017 Core Fulbright US Scholar Award. Alcantar has authored more than 44 publications and book chapters, and holds 10 patents. Her current research interests include interfacial phenomena and chemical characterization of biomimetic membranes, micellar surfactants, green chemistry materials, water purification systems, nanoparticles, and organic/inorganic thin films. Alcantar can be reached by phone at 813-974-8009 or by email at alcantar@eng.usf.edu and norma@usf.edu.
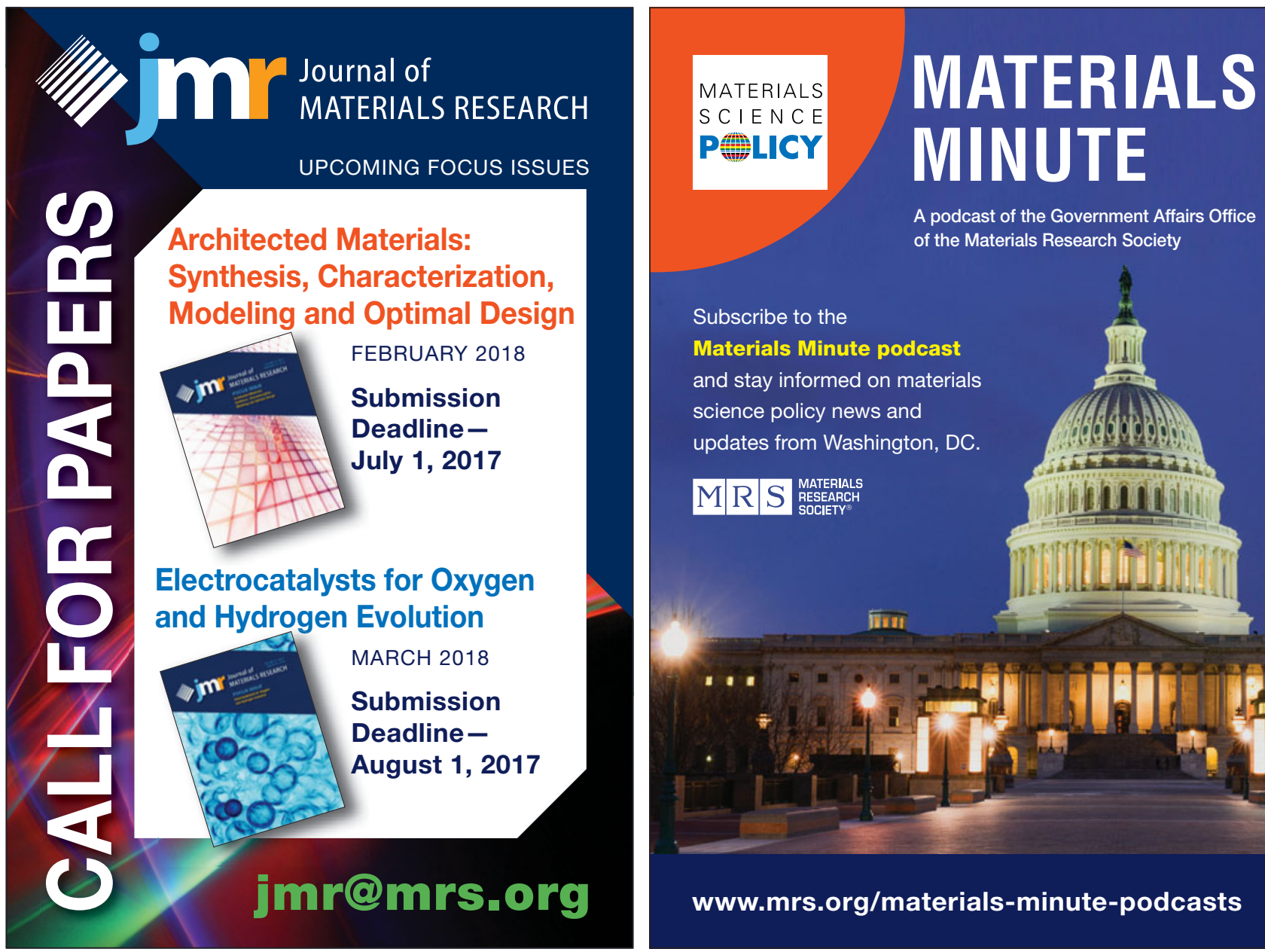

A podcast of the Government Affairs Office of the Materials Research Society

Subscribe to the

Materials Minute podcast and stay informed on materials science policy news and updates from Washington, DC.
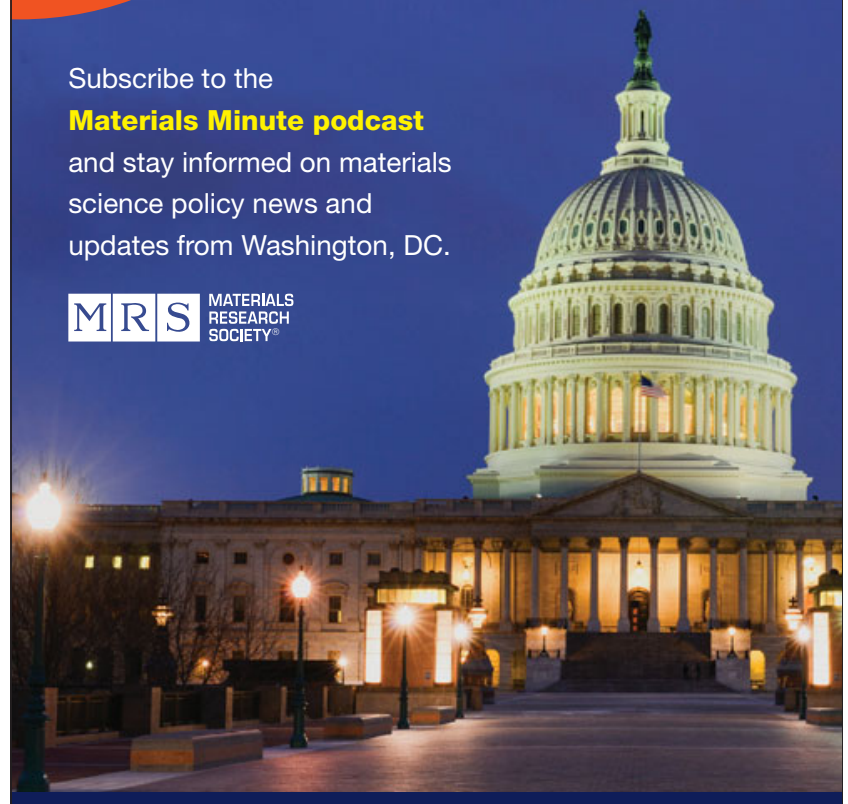

www.mrs.org/materials-minute-podcasts 